\title{
Sudden Death in Incident Dialysis Patients
}

\author{
Eduardo Vázquez ${ }^{a}$ Carmen Sánchez-Perales ${ }^{b}$ Francisco García-García ${ }^{b}$ \\ M. José García-Cortés ${ }^{b}$ Javier Torres ${ }^{a}$ Francisco Borrego $^{b}$ Daniel Salas ${ }^{a}$ \\ Antonio Liébana $^{\mathrm{b}}$ Juan Carlos Fernandez-Guerrero ${ }^{\mathrm{a}}$
}

Departments of a Cardiology and ${ }^{b}$ Nephrology, Complejo Hospitalario de Jaén, Jaén, Spain

\section{Key Words}

Cardiovascular · End-stage renal disease

\begin{abstract}
Background: Sudden death (SD) constitutes one of the principal causes of death and is an important problem in healthcare provision. Cardiovascular diseases have a high prevalence in dialysis patients and constitute the principal cause of death. We sought to analyze retrospectively the incidence of SD in patients commencing dialysis and the factors related to its presence. Methods: We evaluated all the patients who began dialysis in our center between 1/11/2003 and $15 / 9 / 2007$, and who were followed up until death, transplant, or study completion on 31/12/2012. We determined the presence of SD according to the following criteria: SD at $24 \mathrm{~h}$ (SD 24H): unexpected death occurring in the $24 \mathrm{~h}$ following the start of symptoms, or when the patient was found dead and had been seen alive $24 \mathrm{~h}$ earlier; SD at $1 \mathrm{~h}$ (SD 1H): death witnessed as occurring in the first hour following the start of symptoms. Results: We evaluated 285 patients, mean age $65.67 \pm 15.7$ years. In a follow-up of $39.9 \pm 34.2$ months (947.6 patient-years of follow-up) 168 died (59\%), 28 (10\%) patients presented SD 24H (2.9/100 patient-years), and 16 (6\%) patients presented SD $1 \mathrm{H}(1.7 / 100$ patient-years). In the multivariate analysis, having had a myocardial infarction or having had electrocardiographic
\end{abstract}

abnormalities ( $Q$ wave, negative $T$ wave, subendocardial lesion or QRS >120 ms) were the principal independent predictors of SD $24 \mathrm{H}(\mathrm{OR} 7.83 ; 95 \% \mathrm{Cl} 2.20-27.86 ; \mathrm{p}=0.001)$ and of SD 1H (OR 13.43; 95\% Cl 1.56-115.42; $p=0.018)$. Conclusions: SD on dialysis is very frequent. Two groups can be identified easily, with risk profiles clearly differentiated.

(c) 2014 S. Karger AG, Basel

\section{Introduction}

Sudden death (SD) is defined as occurring naturally and unexpectedly following a short period of time varying between 1 and $24 \mathrm{~h}$ from the start of symptoms. It constitutes the principal cause of death in the USA [1] and represents between 6 and $18 \%$ of all deaths. This variability can be attributable to studies having been conducted in different regions and populations, lack of uniformity in defining SD and sudden cardiac arrest, differences in ages of the populations analyzed and, above all, differences in the time lapse between the onset of symptoms and the occurrence of death [2-4].

Cardiovascular diseases have a high prevalence in patients with chronic renal insufficiency and constitute the principal cause of death in this patient population. Despite the information on SD in patients with end-stage renal disease on treatment with dialysis not being exten-

\section{KARGER}

E-Mail karger@karger.com

www.karger.com/ajn
(C) 2014 S. Karger AG, Basel

0250-8095/14/0394-0331\$39.50/0
Eduardo Vázquez, MD

Department of Cardiology, Complejo Hospitalario de Jaén

C/Navas de Tolosa 4 y 6, P-1, $6^{\circ} \mathrm{D}$

ES-23003 Jaén (Spain)

E-Mail vazquez89@arrakis.es 
Table 1. SD types in the dialysis patient population

\begin{tabular}{lccccc}
\hline & $\begin{array}{l}\text { Death } \\
(\mathrm{n}=168)\end{array}$ & $\begin{array}{l}\text { SD 24H } \\
(\mathrm{n}=28)\end{array}$ & $\begin{array}{l}\text { SD 1H } \\
(\mathrm{n}=16)\end{array}$ & $\begin{array}{l}\text { SD weekend } \\
(\mathrm{n}=9)\end{array}$ & $\begin{array}{l}\text { SD dialysis } \\
(\mathrm{n}=6)\end{array}$ \\
\hline \% of all patients $(\mathrm{n}=285)$ & 59 & 10 & 6 & 3 & 2 \\
\% of all deaths $(\mathrm{n}=168)$ & 100 & 17 & 10 & 5 & 4 \\
n/100 patient-years & 18.7 & 2.9 & 1.7 & 0.8 & 0.6 \\
$\mathrm{n} / 100,000$ dialysis sessions & & & & & 5.6 \\
\hline
\end{tabular}

sive, the available data indicate that the frequency is much higher than that in the general population. With an annual incidence of $6-7 \%$, it is responsible for approximately a quarter of all the deaths of patients on dialysis [5]. This high incidence of SD in the population on dialysis relative to the general population is attributed, essentially, to two circumstances. The first is the presence in the dialysis population of the traditional risk factors associated with SD in the general population such as coronary disease, left ventricular hypertrophy, and left ventricular dysfunction. The second circumstance is the effect of the stress, such as electrolyte and plasma volume changes resulting specifically from the hemodialysis treatment, on a heart that is already in a non-healthy state [6]. The time patterns of SD in patients on dialysis show a high incidence during the long interdialysis interval (which is why it is sometimes referred to as 'death which occurs at weekends'), during the dialysis, and the hours following dialysis supports the role of treatment as the main cause of SD $[7,8]$. However, the observation that the incidence of SD in patients treated with peritoneal dialysis is not very different from that of the patients on hemodialysis suggests the determinant cause is the anatomical substrate [9].

The objective of the present study was to analyze retrospectively the incidence of SD in patients who commence dialysis in our hospital and the factors related with the presence of SD.

\section{Patients and Methods}

We evaluated all patients who began dialysis (hemodialysis or peritoneal dialysis) in our hospital and its dependent dialysis centers between November 1, 2003 and September 15, 2007. Excluded were those who had undergone renal transplant, had commenced substitutive treatment at other centers, or who had recovered renal function and had left the dialysis program. The patients were evaluated for cardiac function within the first month of starting dialysis. The evaluation included clinical history, physical examination, electrocardiogram and echocardiogram. The patients were fol- lowed up until death, kidney transplant, or study completion on December 31, 2012.

The occurrence of SD was retrospectively determined, but not all the relevant data were available from the clinical history, i.e. some had died or had changed the place of residence before the performance of the cardiological evaluation, or their data had deteriorated beyond recovery. Hence, although the total number of patients included was 285 , we were able to apply full statistical analyses to a lower number of patients (see tables 1-4). There were 256 patients in whom an echocardiogram had been performed.

SD was established according to the following criteria: (i) SD at $24 \mathrm{~h}$ (SD 24H): unexpected death that occurred within $24 \mathrm{~h}$ following the start of the symptoms, or when the patient was found dead but had been observed to be alive $24 \mathrm{~h}$ earlier; (ii) SD at $1 \mathrm{~h}$ (SD $1 \mathrm{H})$ : death witnessed as having occurred in the first hour following the start of symptoms; (iii) SD in dialysis: unexpected death during a session of hemodialysis, and (iv) SD at weekend: death occurring after $48 \mathrm{~h}$ from the last dialysis session.

The category SD $24 \mathrm{H}$ includes the patients who presented SD $1 \mathrm{H}$ and the patients who presented SD at the weekend. The patients who presented SD during dialysis are included in those who presented SD $1 \mathrm{H}$.

The variables measured in relation to SD were: age, gender, type of dialysis, smoking habit, body mass index, pulse pressure, diabetes, arterial hypertension, presence of previously documented coronary disease (myocardial infarction or coronary lesions $>70 \%$ in the coronary angiography), presence of stroke, transient ischemic attack, heart rate, QRS interval, QTc interval, presence in the electrocardiogram of $Q$ wave, subendocardial lesion (decrease of ST $\geq 1 \mathrm{~mm}$ with horizontal morphology, or descendent) or subepicardial ischemia (negative $\mathrm{T}$ wave in any derivation except in aVR, V1 or D III).

Hematological parameters measured included: hemoglobin, hematocrit, and platelets. Biochemical parameters measured included: urea, creatinine, albumin, cholesterol, HDL cholesterol, LDL cholesterol, triglycerides, C-reactive protein, intact parathormone, calcium, phosphorus, ferritin, transferrin, and homocysteine. Color Doppler echocardiography was used to measure the following parameters: left atrial size, left ventricular dimensions, left ventricular mass, left ventricular ejection fraction, ascending aorta dimension, presence of annular and/or valve calcifications, and mitral E/A ratio.

\section{Statistical Analyses}

Student's t test or the non-parametric Mann-Whitney test was used in the descriptive analysis of the data. Comparison of qualitative variables was carried out with Pearson's $\chi^{2}$ test. Univariate 
Table 2. Differences between those patients who did and those who did not have SD in the previous $24 \mathrm{~h}$

\begin{tabular}{lcccc}
\hline & $\begin{array}{l}\text { All } \\
(\mathrm{n}=285)\end{array}$ & $\begin{array}{l}\text { SD 24H } \\
(\mathrm{n}=28)\end{array}$ & $\begin{array}{l}\text { No SD } \\
(\mathrm{n}=257)\end{array}$ & $\mathrm{p}$ \\
\hline Age, years & $65.67 \pm 15.7$ & $70.69 \pm 10.0$ & $65.12 \pm 16.1$ & 0.013 \\
Left ventricular ejection fraction, \% & $65.09 \pm 9.2$ & $58.91 \pm 11.0$ & $65.69 \pm 8.8$ & 0.001 \\
Left ventricular mass index, g/m ${ }^{2}$ & $165.4 \pm 52.7$ & $177.5 \pm 48.9$ & $164.30 \pm 52.9$ & 0.28 \\
Hemodialysis, n (\%) & $242(84.9)$ & $25(89.3)$ & $217 / 84.4$ & 0.49 \\
Heart rate, bpm & $78.13 \pm 17.6$ & $85.65 \pm 18.6$ & $77.36 \pm 17.4$ & 0.032 \\
Mitral E/A ratio & $0.89 \pm 0.4$ & $0.70 \pm 0.2$ & $0.90 \pm 0.43$ & 0.072 \\
Previous myocardial infarction, \% & $17 / 285(6)$ & $4 / 28(14)$ & $13 / 257(5)$ & 0.050 \\
Q wave & $17 / 253(7)$ & $6 / 24(25)$ & $11 / 229(5)$ & $<0.001$ \\
Subendocardial lesion & $44 / 253(17)$ & $10 / 24(42)$ & $34 / 229(15)$ & 0.001 \\
Negative T wave & $57 / 253(23)$ & $12 / 24(50)$ & $45 / 229(20)$ & $<0.001$ \\
MI or electrocardiographic abnormalities & $103 / 255(40)$ & $18 / 24(75)$ & $85 / 231(37)$ & $<0.001$ \\
Valve calcification & $128 / 256(50)$ & $16 / 22(73)$ & $112 / 234(48)$ & 0.026 \\
\hline
\end{tabular}

Student's t test or Mann-Whitney test for quantitative variables and Pearson's $\chi^{2}$ test for qualitative variables.

Table 3. Differences in those patients with and those without SD in the first hour

\begin{tabular}{lccc}
\hline & $\begin{array}{l}\text { SD 1H } \\
(\mathrm{n}=16)\end{array}$ & $\begin{array}{l}\text { No SD 1H } \\
(\mathrm{n}=269)\end{array}$ & $\mathrm{p}$ \\
\hline Age, years & $73.88 \pm 8.1$ & $65.18 \pm 15.9$ & 0.001 \\
Left ventricular ejection fraction, $\%$ & $57.83 \pm 10.0$ & $65.46 \pm 9.1$ & 0.005 \\
Left ventricular mass index, g/m ${ }^{2}$ & $191.96 \pm 40.2$ & $162.5 \pm 52.9$ & 0.103 \\
Hemodialysis, n (\%) & $13(81.3)$ & $229(85.1)$ & 0.67 \\
Cardiac frequency, bpm & $87.50 \pm 21.2$ & $77.65 \pm 17.3$ & 0.059 \\
Mitral E/A ratio & $0.63 \pm 0.1$ & $0.90 \pm 0.4$ & 0.077 \\
Subendocardial lesion & $7 / 14(50)$ & $37 / 239(16)$ & 0.001 \\
Negative T wave & $7 / 14(50)$ & $50 / 239(21)$ & 0.011 \\
Myocardial infarction or electrocardiographic abnormalities & $10 / 14(71)$ & $93 / 241(39)$ & 0.015 \\
Valve calcification & $11 / 12(92)$ & $117 / 244(48)$ & 0.003 \\
\hline
\end{tabular}

Table 4. Factors independently predictive of SD $24 \mathrm{H}$ and SD $1 \mathrm{H}$

\begin{tabular}{lccc}
\hline Variable & OR & $95 \%$ CI & $\mathrm{p}$ \\
\hline SD $24 H$ & & & 0.001 \\
MI or electrocardiographic abnormalities & 7.83 & $2.20-27.86$ & 0.030 \\
Heart rate & 1.02 & $1.002-1.049$ & 0.018 \\
\hline SD $1 H$ & & & 0.031 \\
MI or electrocardiographic abnormalities & 13.43 & $1.56-115.42$ & 0.040 \\
Heart rate & 1.03 & $1.003-1.056$ & $1.005-1.247$ \\
Age & 1.12 & & \\
\hline
\end{tabular}

Cox's regression of proportional risk, including age, left ventricular ejection fraction, mitral E/A ratio, myocardial infarction or electrocardiographic abnormalities, and valve calcifications.

Sudden Death in Incident Dialysis Patients 
analyses were performed on all measured variables. The objective prognostic variable of this study was the occurrence of SD $24 \mathrm{H}$ or SD $1 \mathrm{H}$. The study was based on an analysis of the predictors at the start of treatment using Cox's regression of proportional risk. The variables included were those that, in the overall patient group, were statistically significant in univariate analysis, or were borderline significant. The odds ratio and 95\% CI were calculated. In all tests, a probability of $\mathrm{p}<0.05$ was considered as statistically significant.

\section{Results}

During the study period, 333 patients had commenced dialysis in our center. Of these, 25 had undergone transplant earlier, 14 had arrived from a different center, and 9 recovered renal function. The remaining 285 were included in the current analysis, and represent $85 \%$ in the hemodialysis program. The mean age was $65.67 \pm 15.7$ years and $55 \%$ were male. During a mean follow-up of $39.9 \pm 34.2$ months (947.6 patient-years of follow-up) 168 patients died (59\%), 28 from SD 24H which represents 2.9/100 patient-years, 16 patients were witnessed deaths SD $1 \mathrm{H}$ (1.7/100 patient-years), 9 patients died during the weekend and 6 during the dialysis sessions. Table 1 summarizes the percentage deaths noted. No autopsies were performed.

Of the 16 patients with SD $1 \mathrm{H}$ (witnessed as having occurred in the first hour of the start of symptoms), 13 were cardiorespiratory arrest with resuscitation failure and without determined cause and, in the 3 remaining patients, the cause of death was established as acute myocardial infarction. In the 12 patients in whom death had occurred in the previous $24 \mathrm{~h}, 8$ were found dead at home. The cause of death was not established although they had been observed alive $24 \mathrm{~h}$ earlier. The other 4 patients died after $1 \mathrm{~h}$ of the start of symptoms, and within a $24 \mathrm{~h}$ time lapse. The cause of death was established as cerebral hemorrhage in 2 patients and mesenteric thrombosis in the other 2 .

The differences in the clinical profile of the patients who died from SD and those who did not are summarized in tables 2 and 3.

The mean ejection fraction was much lower in the patients who presented SD even though both groups were within the normal ranges. Only 2 patients had ejection fraction $<40 \%$ and both presented SD; 1 was SD $1 \mathrm{H}$ and the other was SD $24 \mathrm{H}$ during the weekend. Eight patients had ejection fraction $\geq 40$ and $<45 \%$, and 1 of them presented with SD during dialysis.

Of the 255 patients in whom information and electrocardiographic data were available, 103 (40\%) had pre- sented with previous myocardial infarction or had electrocardiographic abnormalities in the baseline electrocardiogram; these included $\mathrm{Q}$ wave, subendocardial lesion, negative $\mathrm{T}$ wave or QRS $>120 \mathrm{~ms}$. Over a mean follow-up of $39.5 \pm 31.7$ months (median 33.4), 18 of the 103 patients (18\%) who fulfilled some of the criteria presented with SD $24 \mathrm{H}$ and 10/103 (10\%) SD 1H. The rate of SD $24 \mathrm{H}$ was $5.4 / 100$ patient-years in the group with a clinical history of myocardial infarction or electrocardiographic abnormalities versus $0.8 / 100$ patient-years in those patients without these findings. The rate of SD $1 \mathrm{H}$ in the two groups of patients was $2.9 / 100$ and $0.4 / 100$ patient-years, respectively. The Kaplan-Meier curves of the differences in rates of SD $24 \mathrm{H}$ and SD $1 \mathrm{H}$ in the two groups of patients are shown in figure 1. In multivariate analysis, although none of the electrocardiographic alterations individually were shown to be independently predictive of SD, a higher heart rate or a combined variable that included having had a previous myocardial infarction or having electrocardiographic abnormalities were shown to be independent predictors of SD $24 \mathrm{H}$. This latter parameter, together with greater age and elevated cardiac frequency, were the predictors of SD $1 \mathrm{H}$ (table 4).

\section{Discussion}

Our study shows that the frequency of SD in our dialysis population is very high. The rate of SD $1 \mathrm{H}$ and $\mathrm{SD} 24 \mathrm{H}$ were 9.5 and $16.6 \%$ of overall mortality, respectively, and with an annual incidence of 1.7 and $2.9 \%$, respectively.

The annual incidence of SD in the general population in the USA is around $0.1-0.2 \%$ [10] and is around $0.2-$ $0.3 \%$ in the older group of $65-84$ years of age [11]. This represents between 13 and $18 \%$ of all natural deaths in the USA $[2,3]$. In southern European countries the incidence of SD is lower and varies between 0.08 and $0.36 / 100 \mathrm{pa}$ tient-years in the population between 45 and 74 years of age [12]. A perspective on SD mortality in our study needs to take several aspects into account. Firstly, the mortality in the dialysis population is very much higher than that in the general population. Secondly, SD in the general population is observed to have significant regional differences. Thirdly, our study was conducted in a country with the lowest SD rate in the general population [12].

Comparing our data with other studies of SD in dialysis, it is of note that, in American population registries, the annual incidence of SD is also higher than that encountered in the present study. With an annual incidence 


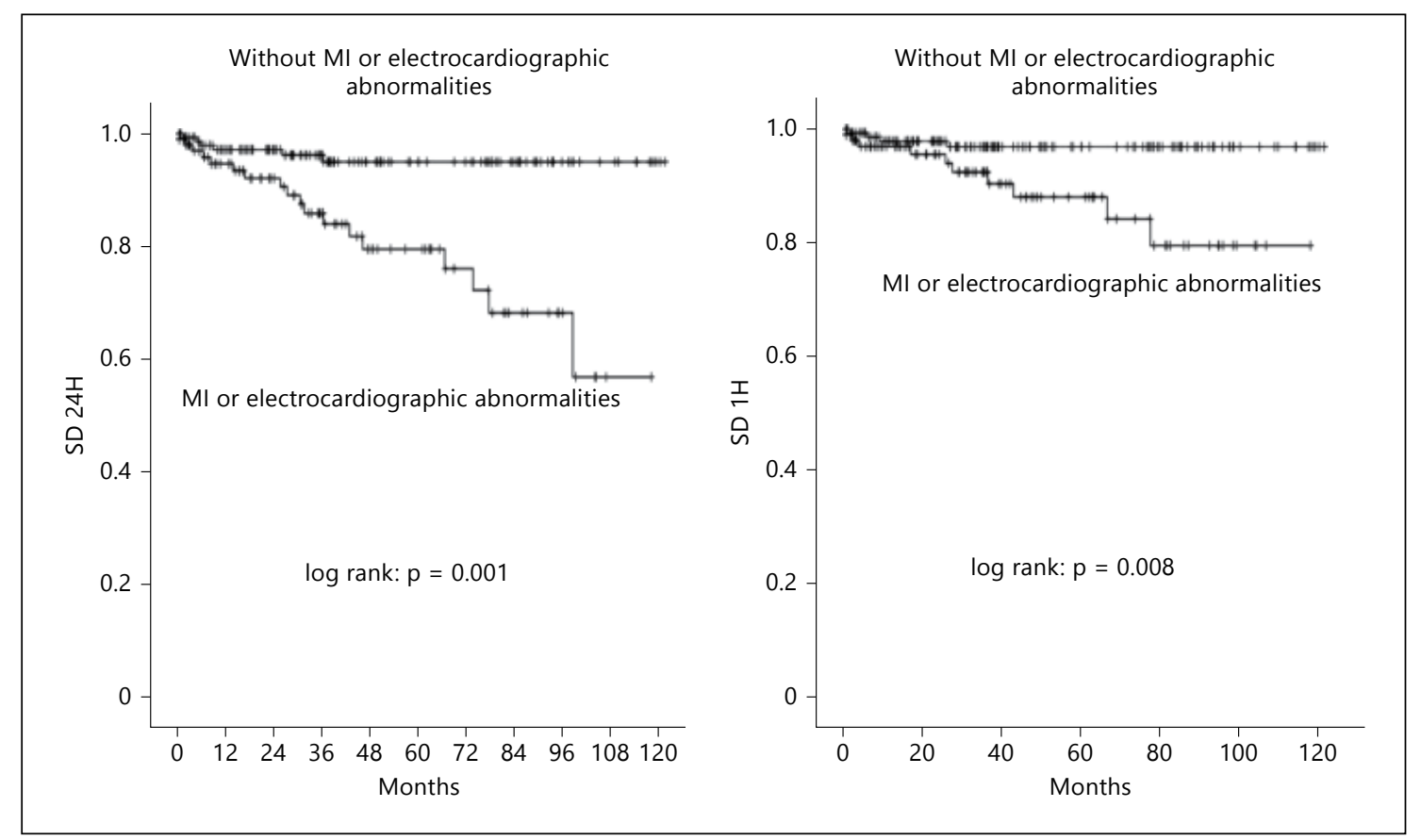

Fig. 1. Kaplan-Meier curves showing the difference in SD between patients with and those without myocardial infarction (MI) or electrocardiographic abnormalities.

of $6-7 \%$, this represents $25 \%$ of all deaths irrespective of the circumstances of the death not being specified nor the time lapse since the start of the symptoms [5]. In clinical trials, SD mortality is lower, and not very different to that of the present study. In the German Diabetes and Dialysis Study (4D Study), 160 of the 1,255 patients (13\%) had SD defined as 'patients who died unexpectedly and did not present with serum potassium $>7.5 \mathrm{mmol} / \mathrm{l}$ before the start of the three most recent sessions of hemodialysis' during a 4-year follow-up [13]. In a study conducted in a single center that included patients on hemodialysis, 32 of the 476 patients included (7\%) died from SD $1 \mathrm{H}$ in a 3 -year follow-up [14], a level slightly higher than that of the present study. The incidence of SD during the dialysis sessions encountered in the present study $(5.6 / 100,000$ sessions) is similar to that observed in the literature in outpatient clinics $(4.5-7 / 100,000$ sessions) $[15,16]$ and lower than that observed in the patients treated in hospitals (12/100,000 dialysis sessions) [17].

In analyzing the factors usually associated with high probability of presenting with SD, we did not find diabetes, type of dialysis, nor C-reactive protein as being independently predictive of $\mathrm{SD}$, as had been found in the study by Genovesi et al. [14]. Atrial fibrillation, which in previous studies conducted in our institution had pre- sented a high prevalence and was associated with higher mortality and greater thrombotic risk [18-20], was not associated with SD in our study, as observed in the study of Genovesi et al. [14]. However, our study identified two groups of risk that were clearly different. The patients who had not had a myocardial infarction and did not have electrocardiographic abnormalities at the start of the dialysis had a rate of SD similar to that observed in the general population. However, those who did have these risk factors were at a sevenfold greater risk of SD.

We believe that identifying a group at high risk of SD in a population with preserved systolic function was the principal finding of our study. The rate of SD $1 \mathrm{H}$ in the patients in the high-risk group in our study $(10 / 103 ; 10 \%)$ had, over a mean follow-up period of $39.5 \pm 31.7$ months (median 33.4), a rate of SD that is similar to that in placebo groups of large general population studies that have evaluated patients with left ventricular systolic dysfunction - groups that constitute a high risk of SD. For example, in the Multicenter Automatic Defibrillator Implantation Trial (MADIT I) [21], 13\% of the patients included in the placebo group had a death attributed to primary arrhythmia during the mean follow-up of 27 months. In the Sudden Cardiac Death in Heart Failure Trial (SCD-HeFT), cardiac mortality resulting from SD 
(presumed to be ventricular tachyarrhythmia) occurred in $11 \%$ of the patients randomized to placebo (median follow-up of 45.5 months) [22].

In conclusion, our study shows that the population on dialysis presents a high incidence of SD and that two groups of patients with very different risk profiles are identifiable. One group with history of myocardial infarction or electrocardiographic abnormalities at the start of the dialysis, albeit with preserved systolic function, constitute a high-risk group for SD similar to that presented in the general population with depressed systolic function. A second group is identifiable without these criteria, and has a risk that is similar to the general population.
More studies are warranted to design an appropriate preventive strategy in the patients with high risk and to establish whether prophylactic therapy with an implanted defibrillator in primary prevention is appropriate in this population. In the light of the information currently available, the efficacy of these devices in patients with systolic dysfunction appears to be much lower in the presence of renal impairment $[23,24]$.

\section{Disclosure Statement}

The authors have no conflicts of interest to disclose.

\section{References}

-1 Myerburg RJ, Kessler KM, Castellanos A: Sudden cardiac death: epidemiology, transient risk, and intervention assessment. Ann Intern Med 1993;119:1187-1197.

$>2$ Kuller L, Lilienfeld A, Fisher R: An epidemiological study of sudden and unexpected deaths in adults. Medicine (Baltimore) 1967; 46:341-361.

>3 De Vreede-Swagemakers JJ, Gorgels AP, Dubois-Arbouw WI, van Ree JW, Daemen MJ, Houben LG, Wellens HJ: Out-of-hospital cardiac arrest in the 1990s: a population-based study in the Maastricht area on incidence, characteristics and survival. J Am Coll Cardiol 1997;30:1500-1505.

-4 Kong MH, Fonarow GC, Peterson ED, Curtis AB, Hernandez AF, Sanders GD, Thomas KL, Hayes DL, Al-Khatib SM: Systematic review of the incidence of sudden cardiac death in the United States. J Am Coll Cardiol 2011;57:794-801.

5 US Renal Data System: USRDS 2010 Annual Data Report: Atlas of Chronic Kidney Disease and End-Stage Renal Disease in the United States. Bethesda, National Institutes of Health, National Institute of Diabetes and Digestive and Kidney Diseases, 2010.

6 Herzog CA, Mangrum JM, Passman R: Sudden cardiac death and dialysis patients. Semin Dial 2008;21:300-307.

7 Foley RN, Gilbertson DT, Murray T, Collins AJ: Long interdialytic interval and mortality among patients receiving hemodialysis. $\mathrm{N}$ Engl J Med 2011;365:1099-1107.

-8 Bleyer AJ, Hartman J, Brannon PC, ReevesDaniel A, Satko SG, Russell G: Characteristics of sudden death in hemodialysis patients. Kidney Int 2006;69:2268-2273.

9 Bleyer AJ, Russell GB, Satko SG: Sudden and cardiac death rates in hemodialysis patients. Kidney Int 1999;55:1553-1559.

10 Myerburg RJ, Kessler KM, Castellanos A: Sudden cardiac death structure, function, and time dependence of risk. Circulation 1992; 85(suppl):2-10.
11 Chugh SS, Jui J, Gunson K, Stecker EC, John BT, Thompson B, Ilias N, Vickers C, Dogra V, Daya M, Kron J, Zheng ZJ, Mensah G, McAnulty J: Current burden of sudden cardiac death: multiple source surveillance versus retrospective death certificate-based review in a large US community. J Am Coll Cardiol 2004;44:1268-1275.

12 Marrugat J, Elosua R, Gil M: Epidemiology of sudden cardiac death in Spain. Rev Esp Cardiol 1999;52:717-725.

13 Drechsler C, Ritz E, Tomaschitz A, Pilz S, Schönfeld S, Blouin K, Bidlingmaier M, Hammer F, Krane V, März W, Allolio B, Fassnacht $\mathrm{M}$, Wanner C: Aldosterone and cortisol affect the risk of sudden cardiac death in haemodialysis patients. Eur Heart J 2013;34:578-587.

14 Genovesi S, Valsecchi MG, Rossi E, Pogliani D, Acquistapace I, De Cristofaro V, Stella A, Vincenti A: Sudden death and associated factors in a historical cohort of chronic haemodialysis patients. Nephrol Dial Transplant 2009;24:2529-2536.

15 Pun PH, Lehrich RW, Honeycutt EF, Herzog CA, Middleton JP: Modifiable risk factors associated with sudden cardiac arrest within hemodialysis clinics. Kidney Int 2011;79:218227.

16 Karnik JA, Young BS, Lew NL, Herget M, Dubinsky C, Lazarus JM, Chertow GM: Cardiac arrest and sudden death in dialysis units. Kidney Int 2001;60:350-357.

17 Lafrance JP, Nolin L, Senécal L, Leblanc M: Predictors and outcome of cardiopulmonary resuscitation calls in a large haemodialysis unit over a seven-year period. Nephrol Dial Transplant 2006;21:1006-1012.

18 Sánchez-Perales C, Vázquez E, García-Cortés MJ, Borrego J, Polaina M, Gutiérrez CP, Lozano C, Liébana A: Ischaemic stroke in incident dialysis patients. Nephrol Dial Transplant 2010;25:3343-3348.
19 Vazquez E, Sanchez-Perales C, Garcia-Garcia F, Castellano P, Garcia-Cortes MJ, Liebana A, Lozano C: Atrial fibrillation in incident dialysis patients. Kidney Int 2009;76:324-330.

20 Vázquez E, Sánchez-Perales C, Lozano C, García-Cortés MJ, Borrego F, Guzmán $M$, Pérez P, Pagola C, Borrego MJ, Pérez V: Comparison of prognostic value of atrial fibrillation versus sinus rhythm in patients on longterm hemodialysis. Am J Cardiol 2003;92: 868-871.

21 Moss AJ, Hall WJ, Cannom DS, Daubert JP, Higgins SL, Klein H, Levine JH, Saksena S, Waldo AL, Wilber D, Brown MW, Heo M; Multicenter Automatic Defibrillator Implantation Trial Investigators: Improved survival with an implanted defibrillator in patients with coronary disease at high risk for ventricular arrhythmia. N Engl J Med 1996;335: 1933-1940.

22 Packer DL, Prutkin JM, Hellkamp AS, Mitchell LB, Bernstein RC, Wood F, Boehmer JP, Carlson MD, Frantz RP, McNulty SE, Rogers JG, Anderson J, Johnson GW, Walsh MN, Poole JE, Mark DB, Lee KL, Bardy GH: Impact of implantable cardioverter-defibrillator, amiodarone, and placebo on the mode of death in stable patients with heart failure: analysis from the sudden cardiac death in heart failure trial. Circulation 2009;120:21702176.

23 Sakhuja R, Keebler M, Lai TS, McLaughlin Gavin C, Thakur R, Bhatt DL: Meta-analysis of mortality in dialysis patients with an implantable cardioverter defibrillator. Am J Cardiol 2009;103:735-741.

24 Goldenberg I, Moss AJ, McNitt S, Zareba W, Andrews ML, Hall WJ, Greenberg H, Case RB; Multicenter Automatic Defibrillator Implantation Trial-II Investigators: Relations among renal function, risk of sudden cardiac death, and benefit of the implanted cardiac defibrillator in patients with ischemic left ventricular dysfunction. Am J Cardiol 2006;98:485-490. 